\title{
A NEW ERIOPHYID SPECIES (ACARI, ERIOPHYIDAE) FROM A SOLANACEOUS WEED IN A TOBACCO CULTURE IN ARGENTINA
}

\author{
Maria Celeste Ballari ${ }^{1}$, Sara L. Quintana de Quinteros $^{2}$, Carlos Holger Wenzel Flechtmann ${ }^{3}$ \\ 1Finca Experimental “La Posta”. Latser AS. Jujjuy, Argentina. E-mail: celesteballari@gmail.com \\ ${ }^{2}$ Universidad Nacional de Jujuy,Argentina. E-mail: zoolagricola@fca.unju.edu.ar \\ 3 Escola Superior de Agricultura “Luiz de Queiroz”, Universidade de São Paulo, Piracicaba, Brasil. E-mail: chwflech@usp.br
}

\section{ABSTRACT}

A new species of Eriophyidae mite, Tetra gibbosa, is described from all motile stages, from a solanaceous weed, Solanumsisymbrifolium, from a tobacco field in Jujuy, Northern Argentina.

Palavras-chave:Eriophyidae, Tetra gibbosa, weed, tobaccofield

\section{UNA NUEVA ESPECIE DE ÁCARO (ACARI, ERIOPHYIDAE) ENCONTRADA EN PLANTACIÓN DE TABACO DE JUJUY, ARGENTINA}

\section{RESUMEN}

Una nuevaespecie de ácaro Eriophyidae,Tetragibbosa, es descripta, en todas sus fases móviles encontradas sobre una maleza,Solanumsisymbrifolium, en una plantación de tabaco de Jujuy, Norte de Argentina.

Keywords:Eriophyidae, Tetra gibbosa,maleza, cultivo de tabaco

\section{INTRODUCTION}

In a recent study of an eriophyid mite on tobacco in Jujuy, Northern Argentina, weeds occurring in this culture were also examined for the presence of this kind of acarine.

one

This investigation already yielded

ShevtchenkellamarceloiFlechtmann on the AsteraceaeTessariadodonaeifoliaweed

(BALLARI et al., 2013) and one species,
RhynacusacerioidesFlechtmann on the solanaceous weed Solanumlorentzii(FLECHTMANN et al., 2014).

The examination of another wild Solanaceae disclosed an eriophyid mite, new to Science, and which is herein described and figured.

All measurements are given in micrometers $(\mu \mathrm{m})$ and refer to the length of the structure, unless otherwise stated. 
For each species, the holotype female measurement precedes the corresponding range for paratypes (given in parentheses).
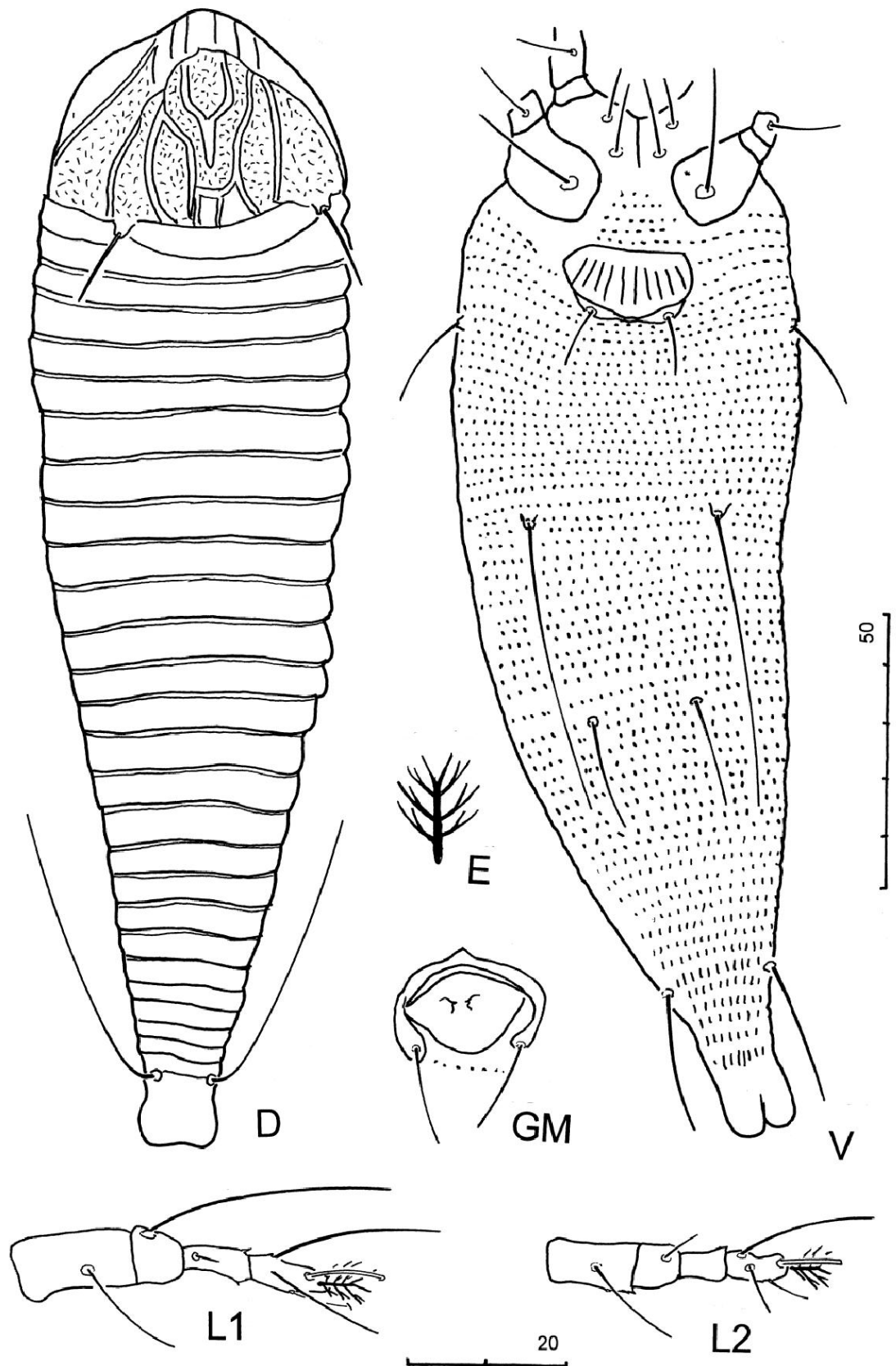

\section{Tetra gibbosan.sp.}

Figure 1.Tetra gibbosaFlechtmann, n.sp. Female. D dorsal habitus; E empodium; L1 leg I; L2 leg II; V ventral habitus. Male. GM malegenitalia. 

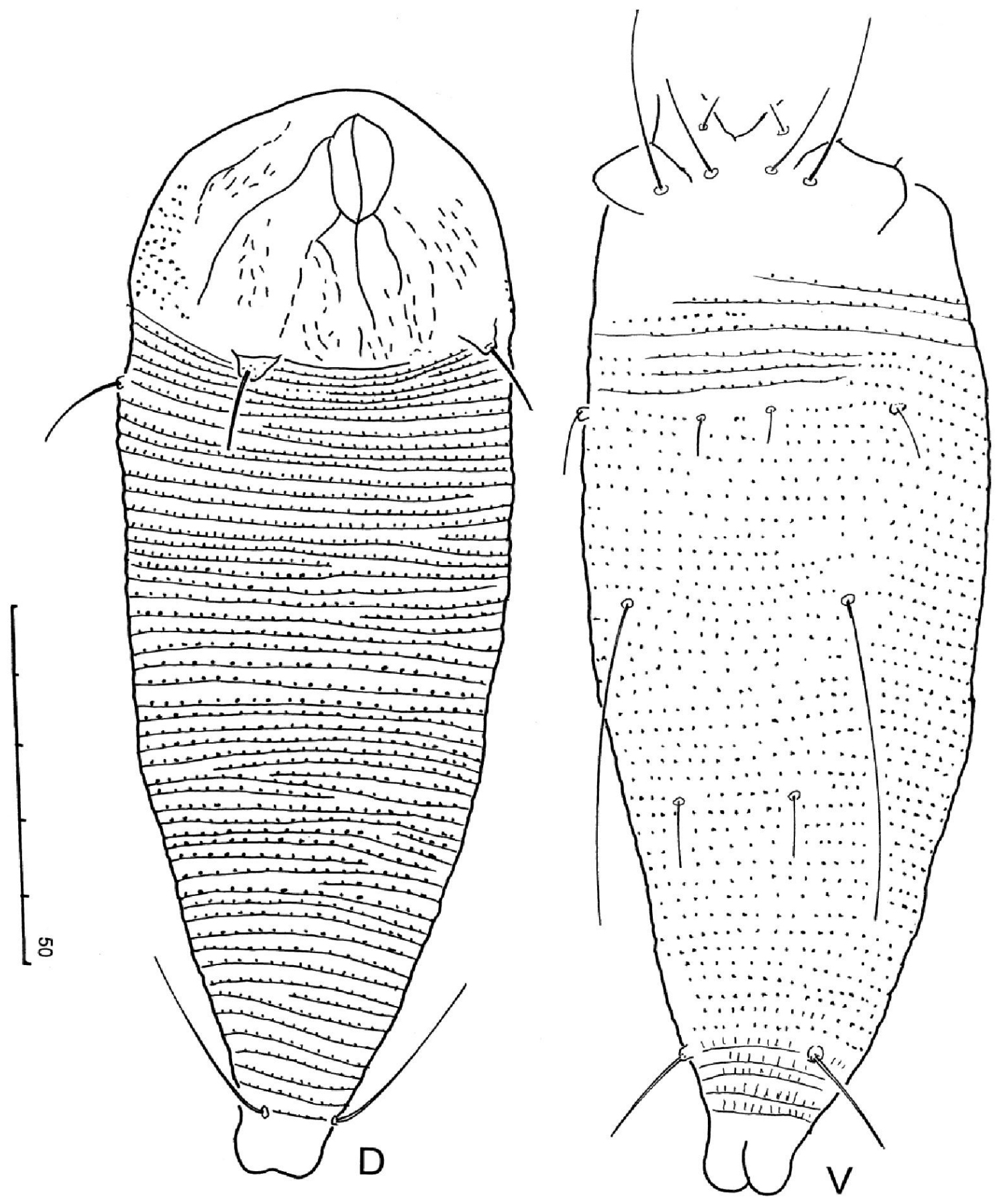

Tetra gibbosan.sp.

Figure 2. Tetra gibbosaFlechtmann, n.sp. Nymph. D dorsal habitus. V. ventral habitus. 
DIAGNOSIS - Prodorsal shield with bulges or callosities, delimited by mainly longitudinal lines forming a unique pattern; anterior lobe broadly rounded. Dorsomedian longitudinal opisthosomal through barely perceptible.

Ventral opisthosomal setae of first pair $(d)$ long, extending past the apex of setae of second pair $(e)$, when both extended backwards.

FEMALE - (specimens measured: 6) Body elongate, fusiform, somewhat flattened dorsoventrally, 198 (188-201), 59 (59-70) widest. Gnathosoma obliquely downcurved; dorsal pedipalpgenual (antapical) seta 3 (35), not branched; palpalcoxal (basal) seta 2 (2); chelicerae 20 (18-20), oral stylets 12 (12-13). Prodorsal shieldsubtriangular, 38 (38-40) including a (3 (3-4) and 16 (16-19) wide frontal lobe; shield 55 (55-61) wide. Shield with dorsal elevations or callosities, delimited by mainly longitudinal lines and one transverse line, as figured; surface of bulges with short irregular dashes. Six short longitudinal lines running from frontal lobe to shiedl anterior region ahead of the callosities. Scapular tubercles on prodorsal shield rear margin, 38 (35-41) apart; scapular seta 13 (13-16), probably directed upwards in living specimens, and backwards in all microscopical preparations. Legs with the usual segmentation and setation. Leg I 31 (31-36); femur 10 (9-11), basifemoral seta (bv) 14 (12-14); genu 3 (3-5), antaxialgenual seta (l”) 30 (27-31); tibia 7 (7-9), paraxial tibial seta ( $l$ ') 6 (4-6), basal; tarsus 7 (7-8), paraxial tarsal seta $(f t$ ') 23 (19-24), antaxial tarsal seta ( $f t$ ") 25 (23-26), paraxial unguinal tarsal seta $(u$ ') 6 (5-7), solenidion 6 (6-9), blunt, empodium 5 (5-7), four-rayed. Leg II 30 (28-33); femur 9 (7-11), bv 14 (12-15); genu 4 (4-5), l' 4 [probably broken] (4-8); tibia 5 (5-7); tarsus 6 (6-8), ft' 7 (5-7), ft'" 22 (33-36), u' 5 (5-6), solenidion 9 (7-9), blunt, empodium 5 (5-7), four-rayed. Coxigenital region: coxae I fused, prosternalapodeme 9 (7-9). Coxal plates smooth, unornamented. Anterolateral seta on coxisternum I (1b) 7 (7-10) , 11 (11-14) apart; proximal setae on coxisternum I (1a) 22 (22-26), 8 (8-9) apart; proximal setae on coxisternum II $(2 a)$ 28 (28-49), 24 (23-26) apart. Coxisternal area with 5 (5-6) faint annuli but easily recognized by their microtubercles. Genitalia 23 (23-28) wide, 15 (13-15) long; epigynum with 10 (10-12) longitudinal ribs. Proximal seta on coxisternum III (relocated to lateral margin of genitalia) (3a) 13 (12-18), with spine-like genital papillae. Opisthosomadorsally slightly flattened, with a barely perceptible medio longitudinal trough. Lateral seta (c2) 19 (19-26), on ventral anulus 4-5 (5-6) counting from first full annulus behind genitalia rear margin. First ventral seta $(d) 55$ (55-63), 37 (37-40) apart, long, extending to apex of consecutive seta, $e$, when both are pointing straight backwards, on annulus 21 (19-22); second ventral seta (e) 18 (17-19), 20 (18-20) apart, on annulus 36 (36-38); third ventral seta $(f)$ 23 (23-25), 18 (18-20) apart, on annulus 55 (55-58) or 5th from rear. Total ventral annuli 60 (60-63), microtuberculate: microtubercles beadlike, small on the first 22 (22-23) annuli, somewhat larger on the next 27 (2729) annuli and slender and increasingly elongate on the posterior annuli. Total dorsal annuli 27 (27-28) counting from first full annulus behind middle of prodorsal rear margin, smooth. Caudal setae (h2) 57 (57$60)$; accessory setae $(h l)$ missing.

MALE (specimens measured: 2) - Smaller than female, 158-172 and 54-55 wide. Gnathosoma: dorsal pedipalpgenual (antapical) seta 4; chelicerae 17-18, oral stylets 11. Prodorsal shield 37-37, including a 3 long and 16-19 wide frontal lobe; shield 47-48 wide. Scapular tubercles 31-37 apart; scapular setae 11-12. Shield ornamentation similar to that of female. Legs.: leg I 29-31; femur 8-10, bv 10-12; genu 4, l' 25-28; tibia 6-7, l' 4; tarsus 7, ft' 
18-19, ft'" 20-21, u' 4, solenidion 7, empodium 6, four-rayed. Leg II 25-27; femur 6-7, $b v$ 8-13; genu 4, l" 4-5; tibia 3-4; tarsus 4-6, ft' 5-6, ft', 18-21, u' 4-5, solenidion 8-9, empodium 6, four-rayed. Coxigenitalregion: presternalapodeme 7-8. Seta $1 b$ 5, 10-11 apart; $1 a$ 16, 7-8 apart; $2 a$ 35, 18-19 apart. Coxisternal annuli 6, microtuberculate. Genitalia 16 wide, 8-9 long; $3 a$ 12-14. Opisthosoma: seta $c 221-23$, on annulus 3-5. Ventral setae $d$ 54-55, 30-33 apart, on annulus 15-19; e 15-16, 17-19 apart, on anulus 28-32; $f$ 20-21, 16-19 apart, on annulus $46-50$ or 5 th from rear. Total ventral annuli 51-55, microtuberculate; total dorsal anuli 27, smooth. Caudal setae (h2) 58-60; accessory setae $(h l)$ missing.

NYMPH (measured specimens: 2) - Body elongate, fusiform, 117-134 and 45-46 wide.

Prodorsal shield 33-35, no anterior lobe. Scapular tubercles 25-26 apart; scapular setae 11. Shield design of one median line, two arched admedian lines connected anteriorly and medially to median line forming an ellypsoid figure; admedian lines extend posteriorly; and one of submedian lines. Shield with scattered longitudinal dashes. Opisthosoma apparently evenly arched in transverse section, annuli mostly continuous dorsoventrally, entirely microtuberculate. Except for the caudal ventral annuli, where microtubercles are slender and elongate, microtubercles are small and beadlike. Total dorsal/ventral annuli 54/50 and 55/48. Ventrally, setae $3 a$ and $c 2$ are on the same annulus.

LARVA (one specimen measured). The only specimen available was not in conditions to allow a drawing, but allowed a few measurements: 110 long, scapular setae 7, prodorsal shield 25 long, surface smooth;opisthosoma with 38 dorsal annuli and 32 ventral annuli.

TYPE MATERIAL - female holotype, 5 female, 2 male, 5 nymph and 2 larval paratypes, on 14 microscopic preparations, from

"espinacolorada",
Solanumsisymbrifolium Lam. (Solanaceae), Jujuy, Argentina, GPS 24 22 ' 51" S, 65 08' 22" W, collectedby M.C. Ballari, in thecollectionof Departamento de Entomologia e Acarologia, Universidade de São Paulo, ESALQ, Piracicaba, SP, Brazil.

RELATION TO HOST - leaf vagrants, no visible damage.

ETYMOLOGY - The specific designation, gibbosa, from the Latin gibbus, meaning humped, refers to the elevations on the prodorsalshiedl.

REMARKS - Tetra gibbosan.sp. resemblesT. intermedia Huang, 2001 (from CoriariaintermediaMatsum, Coriaceae, from Taiwan) in the prodorsal shield line design, however, differs in presenting bulges or callosities ornated with small dashes, absent in T. intermedia.

The new species differs from the other species of Tetra described from Solanaceous plants: from T. martini Manson, 1984, in which the prodorsal shield is unornated, and, from $T$. petuniaeMohanasundaram, 1988, which also has a somewhat similar line pattern on the prodorsal shield, but, otherwise is smooth..

The immatures, larva and nymph, of the new species can be readily distinguished by a character other than size. In the larva the prodorsal shield is only faintly outlined and is unornamented, while in the nymph it is clearly delimited and presents a design of lines and dashes as figured.

TETRA SPECIES FROM SOLANACEOUS PLANTS

The new species, Tetra gibbosan.sp., is the third species of Tetra described from Solanaceous plants. The other ones are:

Tetra martini Manson, 1984, from Solanumaviculare, collected in Waitara, New Plymouth, New Zealand, and

Tetra petuniae Mohanasundaram,1988, from Petunia sp., collected in Varanasi, India.

\section{ACKNOWLEDGEMENTS}


Wethank Dr. Osvaldo Ahumada Cátedra de Botánica General, Facultad de Ciencias Agrarias, Universidad Nacional de Jujuy- for theweed'sidentification.

REFERENCES

BALLARI, M. C., QUINTANA DE QUINTEROS, S. L. \& FLECHTMANN, C.H.W., 2013.A new species of Shevtchenkella (Acari, Prostigmata, Eriophyidae) from Argentina. Revista de Agricultura,Piracicaba, v. 88, n. 3 p. 229-234.

FLECHTMANN, C.H.W., BALLARI, M. C. \& QUINTANA DE QUINTEROS, S. L., 2014. Eriophyoidea (Acari) on Solanaceous plants from Argentina, with description of a new species of Rhynacus (Diptilomiopidae) and a key to species.Systematic and Applied Acarology, Auckland,v. 19, n. 1, p. 7378.

HUANG, K.-W. 2001. Eriophyoid mites of Taiwan: description of eighty-six speceis from the Tengchih area. Bulletin of the National Museum of Natural Science,Taiwan, n. 14, p. 1-84.

MANSON, D.C.M. 1984 Eriophyoidea, exceptEriophyinae (Arachnida: Acari).

Fauna of New Zealand, Auckland n. 4, p.1142.

MOHANASUNDARAM, M. 1988.6 .17 The Eriophyid fauna of Varanasi with description of two new species of Tetra (Acari: Eriophyidae). P. 385-389. In: Channabasavanna, G.P. \& C.A. Viraktamath (eds.) Progress In Acarology, Oxford Publishing Co., p. 1523.

Recebido em: 4/4/2014

Aceito para publicação em: 18/08/2014 